\title{
Life-cycle assessments in the South African water sector: A review and future challenges
}

\author{
Chris Buckley ${ }^{1}$, Elena Friedrich ${ }^{2 *}$ and Harro von Blottnitz ${ }^{3}$ \\ ${ }^{1}$ Pollution Research Group, School of Chemical Engineering, University of KwaZulu-Natal, Durban 4041, South Africa \\ ${ }^{2}$ Centre for Research in Environmental, Coastal and Hydrological Engineering (CRECHE), School of Civil Engineering, \\ Surveying and Construction, University of KwaZulu-Natal, Durban 4041, South Africa \\ ${ }^{3}$ Environmental and Process Systems Engineering Research Group, Department of Chemical Engineering, \\ University of Cape Town, Rondebosch, 7701, South Africa
}

\begin{abstract}
This paper reviews South African water sector life-cycle assessments (LCAs) and develops a position on how this tool could be strategically employed in the future. It summarises the studies undertaken, highlighting the significant findings and the lessons learnt. In addition, international trends and their implications for the local LCA community and the water sector are presented and strategic recommendations for the future are included. The various LCA studies undertaken in the local water industry have shown that the abstraction of water from the environment (in a country where it is a limited resource) and the use of energy for treating and pumping water and wastewater have the highest environmental burdens. These studies have also demonstrated the versatility of LCA as a decision-making tool in the water industry by comparing technologies and scenarios, identifying improvement opportunities and prioritising interventions and their consequences in complex water systems. Recent international work has confirmed the usefulness of a life-cycle approach also for water footprinting. Therefore, in South Africa it is important to promote the use of LCAs for the water sector in order to improve efficiency of processes and systems, but also to promote life-cycle based water footprinting and to include differentiated water consumption data into life-cycle inventories to make more efficient use of water as a resource.
\end{abstract}

Keywords: life cycle assessments, water footprinting, urban water systems

\section{Introduction}

A life-cycle assessment (LCA) is a comprehensive environmental management tool used to investigate the environmental impacts of products, services and activities by taking a 'cradleto-grave' approach. The assessment scope includes the extraction and processing of raw materials, manufacturing, transportation and distribution, use/reuse/maintenance, recycling and final disposal (see Fig. 1). As such, an LCA quantifies inputs and outputs for all these stages and based on this it allows the calculation of environmental scores for defined impact categories (such as global warming, ozone depletion, acidification, smog formation and toxicity to humans, terrestrial and aquatic ecosystems) (ISO, 2006a). These environmental scores are reported for a unit of functionality relevant to the system investigated (referred to as 'the functional unit'). For water systems it is usually a metric unit (e.g. $1 \mathrm{k} \ell$ or $1 \mathrm{M} \ell$ ) of a specified water quality. The use of rigorously derived comparable environmental scores makes LCA a policy-relevant tool for assessing or comparing environmental impacts of products, processes or activities.

The unique capabilities of LCA, as an environmental tool, are its quantitative life-cycle approach which is capable of dealing with complex systems, its comparative capabilities for environmental impacts and its unified methodological approach

This paper was originally presented at the Water Research Commission 40-Year Celebration Conference, Kempton Park,

31 August - 1 September 2011.

* To whom all correspondence should be addressed.

푱 +27 31 260-7709; fax: +27 31 260-1411;

e-mail: Friedriche@ukzn.ac.za (see ISO 14040 (2006a) and ISO 14044 (2006b) documents). In addition, it can detect the shifting of pollution between media (air, water and soil) and different processes. These capabilities led to the widespread use of LCA, including many studies undertaken in the water sector (Friedrich et al., 2007).

\section{LCA water-related studies in SA - a historical development}

LCAs have been used to investigate water-related processes since 1995 (Emmerson et al., 1995) and in time a series of LCA studies have been produced covering many aspects of the water sector. The majority of these studies are summarised in a review by Friedrich et al. (2007). In general, water-related LCA studies have been applied at a strategic and/or regional level, at project and process level and at a very specific (e.g. the choice of different piping materials) level. The majority of these studies emanated from developed countries which developed and shaped the methodology used. However, developing countries are also contributing to the development of the methodology and more of their environmental problems (e.g. water scarcity or salinisation) are being incorporated into the LCA impact categories to be used. South Africa was one of the first developing countries to employ LCAs for water and the Water Research Commission (WRC) had an important role in supporting most of this pioneering work which started in 1999.

\section{The use of LCA for the production of potable water comparing 2 technologies}

The first LCA study in the South African water sector was sponsored by the WRC (Project No. 1077) and compared the 


\section{Life Cycle Assessment: An Overview}

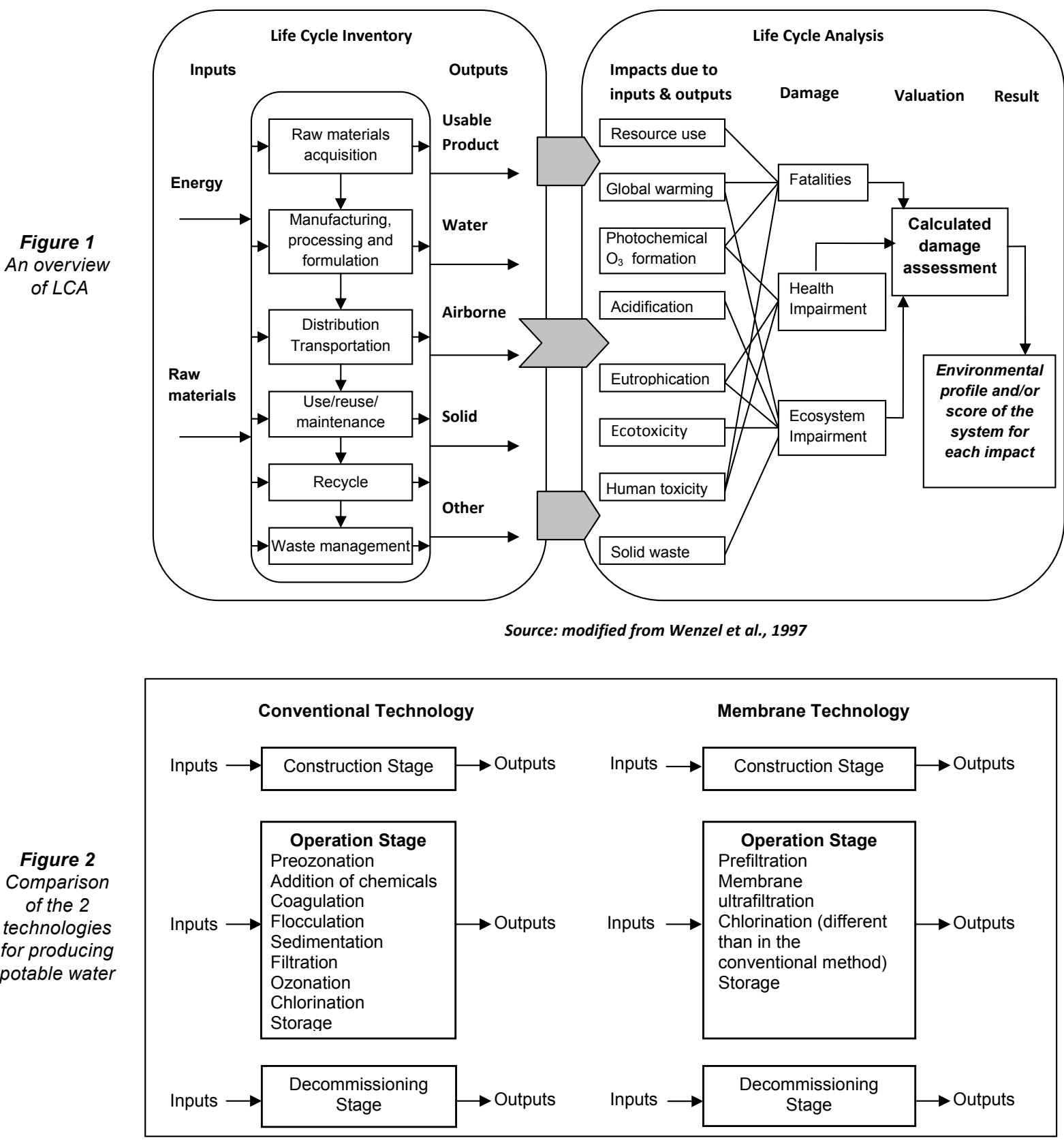

production of potable water by employing 2 different technologies (Friedrich, 2001; Friedrich and Buckley, 2002; Friedrich, 2002). The first technology was the 'conventional method' and was and still is employed at Wiggins Waterworks, a waterworks of Umgeni Water situated in Durban and part of the eThekwini Municipality. The second method was based on the use of a South African membrane filtration technology and at that time there were 3 pilot plants employing this technology in South Africa. An overview of the life-cycle stages and the individual processes involved in each technology is presented in Fig. 2.

The main findings of this project were that the most significant life stage in terms of environmental impacts (as considered by the LCA methodology) was the operational stage and that the main contribution towards the environmental burdens of potable water by both methods was the use of electricity. Ozonation and the treatment of sludge are the processes with the highest burden for the conventional method and pumping and the design layout of the plant have potentially the highest contributions for the membrane-technology treatment. The 2 technologies were comparable from an environmental point of view and the specific recommendations focused on increasing the energy efficiency of both types of waterworks in order to increase their overall environmental performance. Since the low-pressure membrane technology is still under development the membrane process has more scope for optimisation and improvements than the conventional process. This project also highlighted the need for further LCA research within the local water-supply chain as well as for the wastewater resulting from the use of potable water. It also drew attention to the fact that the internationally developed LCA methodology does not address some important, local environmental impacts like water scarcity and salinisation. 


\section{The LCA of an urban water system - the eThekwini case study}

The LCA of an urban water system (WRC Project No, 1252) was a logical continuation of the investigation into the production of potable water and was and still is one of the few international studies taking into account a holistic approach towards urban water (Friedrich et al., 2006; Friedrich et al., 2007; Pillay, 2007; Friedrich et al., 2009a and 2009b). As such it investigated (by means of separate, comparable LCA studies) the abstraction of water from a local dam, the production of potable water in the eThekwini Municipality (Durban Heights and Wiggins Waterworks), the distribution of that potable water in the entire municipality, the collection and treatment of the resultant wastewater and the final disposal of wastewater to sea. In addition, the Durban Water Recycling Plant (which produced industrial-grade water from treated sewage) was investigated and an LCA comparison was performed between the provision of recycled water and 'virgin' potable water to industry (a paper mill and an oil refinery) in the immediate vicinity.

The results for all the individual LCA studies performed for all processes showed that for all these processes the operational stage of the life cycle carries the highest environmental scores. The main contributor to these scores was singled out as being the use of electricity. The use of chemicals played a minor role. These conclusions focused the improvement analysis of individual processes towards energy efficiency measures. In particular, the ozonation process (for the treatment of potable water) and the activated sludge process (for the treatment of wastewater) were targeted. It was also found that recycling of wastewater in this case study has lower environmental scores than the production of the potable water it displaces. However, if the recycled water has to be pumped over long distances and/ or high elevation, the environmental scores of recycled water could easily be higher than those of potable water. The environmental scores of providing bottled water for drinking coupled to a lower water quality in the municipal distribution network were worse compared to the existing water provision scenario.

From the LCAs of individual processes involved in the provision of water and wastewater in the eThekwini Municipality, it emerged that the process with the highest contribution is the activated sludge process. However, when considering the entire system and including the losses in the distribution network for potable water, the component with the highest contribution became the distribution network itself. Therefore, this study has underlined the fact that detailed investigation and optimisation of the environmental performance of urban water systems is complex and that a process approach (through individual
LCAs for the different water processes - abstraction, treatment, distribution, etc.) as well as a system approach (through an overall LCA assessment of the system) are needed. The process approach does not take into account water losses that are inherent to urban water systems and which in the eThekwini case study (and in most South African municipalities) are very important. This conclusion focused the improvement analysis towards reducing supplier and consumer demand, which should lead to lower losses in the system and a more efficient outcome.

\section{The importance of electricity in water LCA studies}

The water, electricity and electricity generation sectors are interconnected. A good illustration of what life-cycle thinking entails arises from the observation that it takes water to make electricity, which again is generally used in water and sanitation systems. Specifically, Eskom (2011) reports in their annual report that the generation of $1 \mathrm{kWh}$ of electricity is associated with the use of $1.35 \ell$ of water (most of this lost in cooling). By way of example, saving $1 \mathrm{k} \ell$ of water by recycling as discussed above and shown in Table 1, would require $0.05 \mathrm{kWh}$ of electricity less than its usual abstraction and treatment, and thus also result in $0.07 \ell$ less water being consumed where this electricity is produced. Table 1 summarises the energy requirements for each water process and the losses at each level in the water system of the eThekwini Municipality. Please note that the $40 \%$ loss at consumer level is returned to the environment but is not collected for treatment (e.g. water used for watering gardens, washing cars, etc.)

Beyond this, electricity use in water system has been highlighted as an important contribution towards the LCA scores of many water studies (Tarantini and Ferri, 2001; Rihon et al., 2002; Stokes and Horvath, 2006; Friedrich et al., 2007) and the first local LCA studies had to use international average data for the calculation of LCA scores. Therefore, it is very important for LCAs in the water sector to be based on a specific South African electricity inventory. Notten (2001) compiled such an inventory but there is now a need for an updated version, and also for further inventories to represent the significant changes that are happening in the South African electricity-generation system.

\section{The development of salinity as an LCA local-impact category}

This study was a subsection of the urban water-system project but it warrants attention on its own. It incorporated one of the most important South African water-quality impacts (i.e. salinisation) into the LCA impact assessment procedure,

\begin{tabular}{|c|c|c|c|}
\hline \multicolumn{4}{|c|}{$\begin{array}{c}\text { Table } 1 \\
\text { Processes investigated in the eThekwini case study and their energy requirements }\end{array}$} \\
\hline Process & $\begin{array}{l}\text { Amount } \\
\text { (ke) }\end{array}$ & $\begin{array}{l}\begin{array}{l}\text { Loss } \\
(\%)\end{array} \\
\end{array}$ & $\begin{array}{l}\text { Energy } \\
(\mathrm{kWh} / \mathrm{k} \ell)\end{array}$ \\
\hline Abstraction of water - Inanda Dam & 1 & 0 & 0 (gravity is used) \\
\hline Purification of water - Wiggins and Durban Heights Waterworks & 0.97 & $1.5 \%$ and $3 \%$ & 0.10 and 0.07 \\
\hline Distribution of water - municipality network & 0.68 & $30 \%$ & 0.10 \\
\hline Use of water - domestic consumers & 0.41 & $40 \%$ & 0 - assumed only for this study \\
\hline Collection of wastewater & 0.41 & $0 \%$ & 0.14 \\
\hline $\begin{array}{l}\text { Treatment of wastewater (total) } \\
\text { Primary } \\
\text { Secondary (clarifiers and activated sludge) } \\
\text { Tertiary (recycling) }\end{array}$ & 0.41 & $0 \%$ & $\begin{array}{l}0.44 \text { of which } \\
0.11 \\
0.28 \\
0.05\end{array}$ \\
\hline
\end{tabular}


adding local value to the internationally developed methodology. This was done through an innovative approach in which a fate model was developed for South Africa, followed by the development of salinity potentials for the country (i.e. for the atmosphere, rivers, natural surfaces and agricultural surfaces). The fate model accounts for the movements of salts between different media (air, soil and water) and calculates expected salt concentrations in these environmental compartments for a 'typical' South African catchment (Leske, 2003; Leske and Buckley, 2004a; 2004b; 2004c). The importance of this work will be fully evident in the future as more water-related LCA studies will be using salinity as an environmental impact.

\section{LCA of water use in South Africa - The Rosslyn industrial area as a case study}

Another WRC-sponsored study (WRC Project No. 1552) making use of LCA was that by Landu and Brent (2006) and Brent and Landu (2007)), which investigated the supply of water to the Rosslyn industrial area, north of Pretoria in the city of Tshwane. This study included the extraction of water from the Vaal River, the purification and pumping at the Zuikerbosch Waterworks, the pumping at the Palmiet station and the storage and gravitation system in the Tshwane Municipality. In the life-cycle impact assessment the authors have used a methodology developed by Brent (Brent, 2003; Brent, 2004; Brent and Visser, 2005) for the different regions of South Africa, which includes normalisation (i.e. relating study-specific impacts to total impacts in a defined region). It represents another important methodological step in making LCAs more relevant to the South African context, because the regional normalisation factors used take into account the fact that water is a scarce resource in different regions in the country. This is an important point that the internationally developed LCA methodology did not consider until 2009 (Pfister et al., 2009). Taking into account the scarcity of water in this country, it is not surprising that the main conclusion of this study was that the 'actual extraction of the water from the ambient environment is in fact the most important consideration' (Landu and Brent, 2006) and therefore, their main recommendation was to reduce water losses. The use of electricity and other energy inputs was seen as important, but to a lesser extent than water itself.

\section{Cleaner production in the mining industry}

Whilst earlier WRC-funded studies investigated the utility and methodological development of LCA specifically, interest then shifted to the inclusion of LCA as one method of investigation within larger studies aiming to reduce water-use related environmental burdens. This was the case for WRC Project No. 1553 (Trusler and Mzoboshe, 2011) which investigated cleaner production $(\mathrm{CP})$ in the mining industry and WRC Project No. 1833 which investigated the environmental sustainability of a large inland industrial complex (reviewed in the following section). The LCA-specific objective of the mining CP project was to conduct focused high-level LCA studies at an overall impact level; to determine priority areas for introducing the CP approach; to acquaint service providers and industry with the technique; and to identify areas to focus on in another part of the project which aimed to set up cleaner production forums. In this project it was confirmed that the linkage between LCAs (which are useful for strategic decision-making) and cleaner production projects (which often focus on improving operations with low-cost or no-cost interventions) can be tenuous.
An LCA was conducted for the drying and use of fine coal currently discarded, mirroring a recommendation arrived at during a cleaner production study in 3 collieries. This LCA concluded that the deportment and management of sulphur contained in the fine coal fraction was the most critical aspect determining whether such an intervention would indeed lead to a 'cleaner' outcome, being the key to acidification impacts that already plague the mining sector's relation to water-quality deterioration. The usage of such recovered fine coal in a power station equipped with flue gas desulphurisation would reduce all environmental burdens over a base-case scenario where this potential resource is disposed of and more coal has to be mined - with attendant environmental burdens - for a set power output. The current practice of solar drying for use in domestic power generation without flue gas desulphurisation was found to reduce some environmental burdens (notably abiotic resource depletion) but to shift burdens in other categories (notably for acidification).

\section{A comparative LCA of process water technologies at the Secunda complex}

WRC Project No. K5/1833 investigated factors that influence the environmental sustainability of the large inland industrial complex around the Sasol synfuels production site at Secunda, defined to include the Tutuka Power Station as well as the coal mines supplying both sites (Ras, 2011). A key environmental sustainability concern identified relates to the management and storage of water-soluble salts; a related concern is the large dissipative water use dictated by the poor thermal efficiency of key processes in the complex. Several cleaner production options that would involve the cooperation of two or more industries were considered. One such technological intervention was then investigated in detail by means of an LCA.

The industries and power stations in this complex treat raw water prior to industrial use, especially for boilers. Two different raw-water desalination technologies, an existing ionexchange plant and a proposed reverse osmosis intervention, were compared. Significantly, the assessment predicted the reverse osmosis option to effect a $78 \%$ overall reduction in storage of problematic salts, from $599 \mathrm{~kg} / \mathrm{M} \ell$ to $133 \mathrm{~kg} / \mathrm{M} \ell$ of raw water treated. This large reduction of the salt burden in the target industry would result in an increase in salt generation and storage at the supplying power station of less than $1 \%$ of that avoided, i.e. virtually no shifting of the burden. This was despite the power station in the complex using mine-water desalination and thus producing power with an uncharacteristically high salt footprint. The reverse osmosis option would, however, perform $22 \%$ worse for global warming potential, as it would use more coal-derived electricity. An interesting aside was that the intervention would reduce burdens of the ion-exchange option on human toxicity and freshwater aquatic ecotoxicity, which are due to the use of an aluminium sulphate coagulant. The life-cycle assessment thus demonstrated that an overall reduction in salinisation risk could be achieved in this large complex by a technology change in one of the operations.

\section{Lessons learnt}

The studies presented show that LCA is a valuable and versatile tool for the water sector. It can be used as a 'focusing' tool to increase the efficiency of existing water processes and/or systems but also as a 'comparative' tool to direct decision-making for future water-related developments and technologies. In 
particular, the quantitative and holistic approach of the LCA methodology makes this tool suited for scenario analysis which should lead to more informed decisions and better overall outcomes for the water sector itself but also for other sectors in which water is an important input. To achieve these outcomes LCA can be applied at different levels of sophistication from life-cycle thinking to detailed, data-intensive studies.

It is well-known, and was confirmed in all the above studies, that a full life-cycle assessment is data-intensive and can only be completed within reasonable time if process data and emissions inventories are well kept. Full life-cycle assessments are therefore expensive in terms of expert human resources, and should be carried out only to inform strategic decisionmaking, where the stakes, the complexity and the uncertainty tend to be high.

For more frequently occurring decisions of a tactical nature (e.g. investments using an already proven technology), lessons learnt from detailed LCAs should be adaptable if a life-cycle thinking approach is taken. Such lessons include:

- The most significant life stage in terms of environmental impacts is the operational stage.

- The majority of the environmental impacts are traced to electricity production.

- Ozonation and activated-sludge technologies have the highest environmental burdens due to their high energy consumption. Optimising these processes will bring about most savings.

- Local low-pressure membrane technologies used for the production of potable water can have comparable environmental burdens to existing, conventional technologies, but they have more scope for future optimisation and improvements

- Ion-exchange technology can amplify salinity burdens.

- Improvements in large-scale water systems can be achieved by considering individual processes within those systems but also by investigating each system as a whole with emphasis on water losses between processes.

- Water losses in the reticulation and distribution system multiply the environmental burdens, including the most significant environmental impact of water extraction itself.

- The activated-sludge process has the highest environmental burdens in the treatment of wastewater, therefore, where appropriate, safe on-site sanitation should be promoted.

It is noteworthy that environmental LCA scores of water systems are relatively low compared to those of other systems such as transportation, energy production, etc. For example, assuming $0.93 \mathrm{~kg} \mathrm{CO}$ equiv $/ \mathrm{k} \ell$ water provided to consumers (as calculated in the eThekwini study) and assuming a consumption of $50 \ell$ water/person $\cdot \mathrm{d}$, it results in $17 \mathrm{~kg} \mathrm{CO}_{2}$ equivalent being produced per person per year due to the provision of water and wastewater services. It is estimated that overall greenhouse gas emissions for South Africa are about $10 \mathrm{t} \mathrm{CO}_{2}$ equiv/cap·a (Republic of South Africa - The Treasury, 2010). Therefore, this illustrates that the per capita contribution due to water and wastewater services is very small. The overall social benefits (health, development, etc.) of having water systems in place by far outweigh the environmental burdens modelled by the LCA methods. That notwithstanding, LCA studies are useful in order to optimise and improve existing and future water-related processes and systems, especially when operational expenses and environmental impacts from inefficient usage of inputs such as electricity or chemicals coincide, providing a double incentive to improve performance.
In terms of capacity-building, the first LCA projects sponsored by the WRC led to an international collaboration with the Danish Technical Institute in Copenhagen (Prof H Wenzel). All projects included the transfer and dissemination of LCA knowledge within SA, e.g. to specialist consulting engineering firms partnering with academia on some of the projects. Workshops were offered at the WISA conferences held in 2000, 2002, 2004 and 2010. These workshops introduced LCA to the broader audience in the water sector and also, in general, to government, consultants and academics and led to the formation of the first informal LCA network in the country. As a result of these projects, numerous scientific articles were published in international and local journals and many conference papers were presented. These WRC projects also led to the awarding of 3 doctoral and 3 masters degrees, building up local expertise in the LCA field.

\section{International trends in LCA/LCM (life-cycle management) and their relevance to $S A$}

The life-cycle assessments reviewed in the first part of this paper were generally process orientated, asking which decisions in process selection and (re-)design of water or sanitation systems were most likely to allow for overall burden reduction, or to result in the shifting of burdens. This type of LCA usage has a tradition of more than 15 years and is common also to other sectors (e.g. chemical, metallurgical, waste management). It is likely to continue to be used in the future in many sectors, and stands to gain from significant improvements in the availability of background datasets, both in terms of quantity and geographical coverage. By way of example, the $3^{\text {rd }}$ release of the ecoInvent Database announced for 2012 will more than double the number of datasets offered to well above 10000 , and will also cover $90 \%$ of the global electricity production. Progress in this type of LCA usage is likely to be threefold:

- More, and more reliable LCA studies

- Development of sector-specific life-cycle competent assessment tools that can give rapid results

- Better design guidance without the necessity for full LCA studies to be undertaken, using an emerging life-cycle technique referred to as 'knowledge mining' or 'knowledge harvesting', drawing generic lessons from prior studies

However, this process-focused type of LCA accounts only for a small fraction of LCA work globally, with product-oriented LCAs being much more common. Significantly, within this latter product-focused category, water-related impacts are of strong and growing concern. Here, water-polluting substances and their effects (e.g. aquatic ecotoxicity, eutrophication and salinity) are well covered in LCA methodology, but more recently, water usage has become a topic of major interest, embodied in the term 'water footprinting', discussed in more detail below. In parallel, there is much interest in extending LCA from an environmental focus to 'life-cycle sustainability assessment' by adding so-called social life-cycle assessment (SLCA) and life-cycle costing (LCC). However, whilst the UNEP-SETAC Life Cycle Initiative has issued a guide for social LCA, there remains much disagreement in the literature as to the purpose and method for doing such work.

\section{Water footprinting}

With regard to the application of life-cycle thinking for water resources, a recent international trend has to be highlighted, 
namely the development and increased use of water footprinting. This is a concept and an environmental tool accounting for the volumes of water used and degraded by humans directly and indirectly. Water footprints can be calculated for products (services or activities), for consumers (at local, regional, national and international levels) and for organisations (Hoekstra, 2008). In particular, water footprinting takes into account that 'international trade affects the global pattern of water use' (Hoekstra, 2008) and that exported and imported goods carry with them their embedded (also called virtual) water as used along the supply chain for these goods. This has particular implications for South Africa as an exporting, waterscarce country. Blue, green and grey (surface water/groundwater, rain/evaporated water and polluted water, respectively) water footprints have been defined in the literature and methodologies for the calculation of each of these footprints have been developed and are being refined (Hoekstra and Chapagain, 2008). There are initiatives towards standardising the methodology and recently a manual for water footprinting has been developed (Hoekstra et al., 2011). There is also an initiative towards the development of an ISO water footprint standard to fall in line with the current ISO standards for life-cycle assessment. The standard, ISO/WD 14046 (ISO, 2011), is currently under review and is scheduled to be released in its final form by the end of 2013.

In South Africa a few studies to calculate water footprints have been undertaken, most notably the study initiated by SABMiller and WWF-UK for the production of beer (2009) and the water footprint undertaken for the Breede River catchment (Western Cape Province) by Pegasys Consultants (2010). The SABMiller study showed that for the production of $1 \ell$ of beer in South Africa $155 \ell$ of water are used, whereby for the production of $1 \ell$ of beer in their Czech subsidiary $45 \ell$ of water is used. Most of the water used (over 90\%) in both cases was due to cultivation of crops used for beer production. Local factors such as higher evaporation rates and intensive irrigation explained the higher water footprint of the South African beer. Even within South Africa, barley sourced from different regions had different water footprints. The Breede River catchment study showed that different water uses in the area (for crops or other activities) generate different returns in terms of value and employment and that there are 'efficient' and 'inefficient' uses of water within the catchment. These 2 applications highlight the value of water footprinting in the context of water-resource management in South Africa and the need to have more such studies undertaken. In particular, the role of South Africa as an importer of water (e.g. the Lesotho Highlands scheme), which is incorporated in products exported is in need of research, because water footprints, as any environmental metrics (i.e. LCA scores, carbon footprints), are used for benchmarking in global markets. In general, with regard to LCAs and water footprints, more research is also necessary in order to understand the use and the integration of these 2 tools in the local context.

Studies on water footprints in the mining industry are also seen as important. In general, water-accounting studies, limited to within site boundaries, have often been performed. A study to expand this to water footprinting is to be performed by the University of the Witwatersrand (as part of the South African Minerals to Metals Research Initiative). This study will investigate various water-footprinting techniques, including the methods of Hoekstra (2008), the ISO 14046 methodology as well as the traditional water-accounting method, using an approach (Water Miner) developed by the Sustainable
Minerals Institute of the University of Queensland (University of Queensland, 2011).

There are similarities and differences between LCA and water footprinting. Both methods have a life-cycle approach, but they focus on different issues. Water footprinting focuses on water resource management, showing in space and time volumes consumed by source (green and blue water footprints) and volumes polluted (grey-water footprints) for the production of a product over the entire supply chain (Hoekstra and Chapagain, 2008). LCA studies investigate many environmental impacts (global warming, acidification, toxicity, etc.) and typically include the impacts not only for the supply chain but also for the consumption and the disposal of a product. These impacts are summed over many geographical locations. LCA studies do include water consumption in the inventory; however, until recently (2009) the impacts of water abstraction and consumption were not assessed. The LCA methodology did not take into account if the water used came from water-stressed, dry areas or from water abundant, wet areas. With the development of a water-use impact category for LCAs (Pfister et al., 2009), these shortcomings have been addressed. However, some LCA users shy away from incorporating water-use impacts because of the complexity and uncertainties involved and because water data needed for such assessments are not always available (Cooney, 2009). With the development of the ISO 14046 standard, these concerns should be alleviated.

In South Africa there is no experience with the use of the LCA water-assessment impacts developed by Pfister et al. (2009). The implications they have for local studies has to be researched since different areas of the country present different degrees of water stress. In addition, the way the new methodology is linked to water footprinting in the local context has to be investigated.

\section{Strategic directions for future application of LCA and life-cycle thinking in the water sector}

To date, in water-related studies, LCA has been used to analyse complex systems, to identify high-impact activities, to compare technologies/processes and to a lesser degree to guide improvement trajectories and set research priorities. In relation to these applications we note 8 important future directions for LCAs in the water sector and for system-wide minimisation of waterrelated environmental impacts:

- LCA and life-cycle thinking should be used regularly for water-related planning, decision-making and debates. Although there are considerable advantages of using these tools, at the moment in South Africa, LCAs and water footprinting studies have been confined to academic circles and a few consultancies. It is important to increase penetration of LCA into water-related decision-making at local, provincial and national levels and the WRC is strategically positioned to play an important role in this process, not only in the generation of LCA local knowledge but also in the dissemination of this knowledge. For example, LCA should be used in the evaluation of sanitation policies, in the evaluation of acid mine drainage options and in the industrial effluent discharge permitting process.

- The development of a South African database and possibly of simplified LCA software for water-related processes and systems would be an important step towards making LCA more user friendly in the local water sector.

- Water systems will become more complicated, with cascading and cycling of water making future assessments of 
process design choices less trivial. This requires a continued focus on the application and correct usage of LCA by water-infrastructure planners and decision-makers.

- Water footprinting has already attracted some attention in South Africa, and there are current international efforts to align its methodology with that of LCA. This presents an opportunity for more local research and development on the integration of water footprints and LCA.

- The emergence of product-level (and product-category level) LCAs as important information-providing tools for the sustainable consumption movement is already evident in advanced economies. This means that embodied water and water pollution of exported goods is already influencing the decision-making of product designers and industrial buyers of South African goods. Additionally, there are already early adopters of product-level LCAs in South Africa, who are anticipating their local buyers (especially the retail sector) to be using such information more frequently.

- An emerging discipline in South Africa is the determination of the Ecological Reserve within the context of river flow allocation. An associated activity is the concept of the goods and services provided by ecological systems such as wetlands. This results in the need for a trade-off between engineered systems and environmental concerns. LCA studies could provide guidance in bridging the 2 approaches in order to arrive at a transparent compromise.

- The increasing need to provide potable-quality water from sewage and the use of treated sewage for food production provides an opportunity to link environmental issues (LCA studies) and health issues (expressed as disability adjusted life years) in local case studies.

- LCA could be also used as a quantitative tool to assess eutrophication in general and in particular the health effects of releasing wastewater that has not been properly treated.

Water can be considered as both a renewable and a non-renewable resource depending on geographic context and time scale. Thus the exploitation of a particular water resource needs to be viewed in the context of competing uses for that resource. LCA and water footprinting studies are able to quantify the complex effects of resource exploitation and help mediate strategic solutions.

\section{Conclusions}

LCA studies and in general life-cycle thinking are emerging as very useful tools in the investigation and decision-making for the water sector, as well as in the management of water as a resource. The different LCA studies undertaken in the local water industry have shown that the abstraction of water from the environment (in a country where it is a limited resource) and the use of energy for treating and pumping water have the highest environmental impacts. For the water and sanitation systems the environmental scores for these impacts are dominated by the use (also termed operational) phase, within which energy and chemical usages are important. These may be minor relative to impacts of other sectors and may well be justifiable by the societal gains of clean water and sanitation, but that is no excuse not to minimise such impacts across the life cycle and make urban, industrial and agricultural water systems more efficient (i.e. lower water losses which magnify the burdens). This will become more important and less trivial as water infrastructure becomes more complicated with cascading and (re)cycling of water.
In a water-scarce country, both the water extraction itself, and water-quality related impacts such as salinisation, should be considered in any life-cycle assessment, whether in the water sector or not. Water footprinting may cover these matters to some extent, and there is important, recent and current international work that seeks to build the rigour of LCA into water footprints, which calls for more local research and development on this front. More specialists need to be trained to be able to make use of these valuable tools for decision-making.

\section{Acknowledgements}

The WRC is acknowledged for its vision and sustained support for the development of life-cycle assessment in the South African water sector. All of the studies reviewed in this paper were supported by the WRC.

The authors wish to express their gratitude to Dr Kevin Harding (School of Chemical and Metallurgical Engineering, University of the Witwatersrand, Johannesburg) for his contribution towards the section on water footprinting.

\section{References}

BRENT AC (2003) A proposed lifecycle impact assessment framework for South Africa from available environmental data. S. Afr. J. Sci. $99(3 / 4) 115-122$

BRENT AC (2004) A life cycle impact assessment procedure with resource groups as areas of protection. Int. J. Life Cycle Assess. 9 (3) $172-179$.

BRENT AC and VISSER JK (2005) An environmental performance resource impact indicator for life cycle management in the manufacturing industry. J. Clean. Prod. 13 (6) 557-565.

BRENT AC and LANDU L (2007) Environmental Life Cycle Assessment of Water Use in South Africa: The Rosslyn Industrial Area as a Case Study. WRC Report No. 1552/1/02. Water Research Commission, Pretoria, South Africa.

COONEY C (2009) LCA finally takes water into account. Environ. Sci. Technol. 43 (11) 3986.

EMMERSON RHC, MORSE GK, LESTER JN and EDGE DR (1995) The life-cycle analysis of small scale sewage-treatment processes. J. CIWEM. 9 317-325.

ESKOM (2011) Fact sheets - Managing our Impact on the Environment. URL: http://financialresults.co.za/2011/eskom ar2011/ fact sheets 03.php (Accessed September 2011).

FRIEDRICH E (2001) The Use of Environmental Life Cycle Assessment for the Production of Potable Water. M.Sc. Eng. Thesis. Pollution Research Group, University of KwaZulu-Natal, Durban, South Africa.

FRIEDRICH E and BUCKLEY CA (2002) The Use of Life Cycle Assessments in the Selection of Water Treatment Processes. WRC Report No. 1077/1/02. Water Research Commission, Pretoria, South Africa.

FRIEDRICH E (2002) Life cycle assessment as an environmental management tool in the production of potable water. Water Sci. Technol. 46 (9) 29-36.

FRIEDRICH E, BUCKLEY CA, PILLAY S and LESKE A (2006) A Life Cycle Assessment of a Secondary Water Supply. WRC Report No. 1252/1/06. Water Research Commission, Pretoria, South Africa.

FRIEDRICH E, BUCKLEY CA and PILLAY S (2007) The use of LCA in the water industry and the case for an environmental performance indicator. Water $S A 33$ (4) 443-451.

FRIEDRICH E, BUCKLEY CA and PILLAY S (2009a) Environmental life cycle assessment - a South African case study of an urban water cycle. Water SA 35 (1) 73-84.

FRIEDRICH E, BUCKLEY CA and PILLAY S (2009b) Carbon footprint analysis for increasing water supply and sanitation in South Africa - a case study. J. Clean. Prod. 17 (1) 1-12. 
HOEKSTRA AY and CHAPAGAIN AK (2008) Globalisation of Water: Sharing the Planet's Freshwater Resources. Blackwell Publishing, Oxford, UK.

HOEKSTRA AY (2008) Water Neutral: Reducing and Offsetting the Impacts of Water Footprints. Research Report Series No.28, UNESCO-IHE. URL: http://www.waterfootprint.org/Reports/ Report28-WaterNeutral.pdf (Accessed September 2011).

HOEKSTRA AY, CHAPAGAIN AK, ALDAYA MM and MEKONNEN MM (2011) The Water Footprint Assessment Manual: Setting the Global Standard. Earthscan, UK.

ISO 14040 (2006a) Environmental Management - Life Cycle Assessment - Principles and Framework. International Organisation for Standardisation, Geneva, Switzerland.

ISO 14044 (2006b) Environmental Management - Life Cycle Assessment - Requirements and Guidelines. Organisation for Standardisation, Geneva, Switzerland.

ISO/WD 14046 (2011) Life Cycle Assessment - Water Footprint Requirements and Guidelines, Organisation for Standardisation, Geneva, Switzerland. URL:http://www.iso.org/iso/iso catalogue/ catalogue tc/catalogue detail.htm?csnumber $=43263$ (Accessed September 2011)

LANDU L and BRENT AC (2006) Environmental life cycle assessment of water supply in South Africa: the Rosslyn industrial area as a case study. Water $S A 32$ (2) 249-256.

LESKE A (2003) The Development of a Method for Inclusion of Salinity Effects into Environmental Life Cycle Assessments. Ph.D. Thesis. Pollution Research Group, University of KwaZulu-Natal, Durban, South Africa.

LESKE A and BUCKLEY CA (2004a) Towards the development of a salinity impact category for South African life cycle assessments: Part 1 - A new impact category. Water SA 29 (3) 289-296.

LESKE A and BUCKLEY CA (2004b) Towards the development of a salinity impact category for South African life cycle assessments: Part 2 - A conceptual multimedia environmental fate and effect model. Water SA 30 (2) 241-252.

LESKE A and BUCKLEY CA (2004c) Towards the development of a salinity impact category for South African life cycle assessments: Part 3 - Salinity potentials. Water SA 30 (2) 253-264.

NOTTEN P (2001) Life Cycle Inventory Uncertainty in Resource Based Industries - A Focus on Coal Based Power Generation. Ph.D. Thesis. University of Cape Town. Cape Town, South Africa PFISTER S, KOEHLER A and HELLWEG S (2009) Assessing the environmental impacts of freshwater consumption in LCA. Environ. Sci. Technol. 43 4098-4104.

PEGASYS - STRATEGY AND DEVELOPMENT (2010) Water Footprint Analysis for the Breede Catchment, South Africa. URL; http://bocma.co.za/docs/2010/BreedeWMA WaterFootprintReport Aug10.pdf (Accessed September 2011).

PILLAY SD (2007) An Environmental Life Cycle Assessment of the Provision of Recycled Water in Durban. Ph.D. Thesis. Pollution Research Group, University of KwaZulu-Natal, Durban, South Africa.

RAS C (2011) An Industrial Ecology Approach to Salt-Related Environmental Sustainability Issues in a Large Industrial Complex. M.Sc. Eng Thesis. University of Cape Town, Cape Town, South Africa.

REPUBLIC OF SOUTH AFRICA - NATIONAL TREASURY (2010) Reducing greenhouse gas emissions: The tax option. Discussion paper for public comment. URL: http://www.treasury.gov.za/ public $\% 20$ comments/Discussion $\% 20$ Paper $\% 20$ Carbon $\% 20$ Taxes\%2081210.pdf (Accessed September 2011).

RIHON AC, LASSAUX S and GERMAIN A (2002) Application of the LCA methodology to water management from the pumping station to the wastewater treatment plant. Proc. $10^{\text {th }}$ SETAC LCA Case Studies Symp., 2-4 Dec 2002, Barcelona, Spain.

SABMILLER and WWF-UK (2009) Water footprinting: Identifying and addressing water risks in the value chain. URL: http:// www.sabmiller.com/files/reports/water_footprinting_report.pdf (Accessed September 2011).

STOKES J and HORVATH A (2006) Life cycle energy assessment of alternative water supply. Int. J. LCA 11 (5) 335-343.

TARANTINI M and FERRI F (2001) LCA of drinking and wastewater treatment systems of Bologna City: Final results. Proc. $4^{\text {th }}$ IRCEW Conf., 27-30 August 2001, Fortalenza, Brazil.

TRUSLER G and MZOBOSHE S (2011) The Introduction of Cleaner Production Technologies in the South African Mining Industry - Volume 1. WRC Report No. 1553/1/11. Water Research Commission, Pretoria, South Africa.

UNIVERSITY OF QUEENSLAND (2011) Water Miner. URL: http:// waterminer.smi.uq.edu.au/ (Accessed September 2011).

WENZEL H, HAUSCHILD, M and ALTING L (1997) Environmental Assessment of Products - Volume 1: Methodology, Tools and Case Studies in Product Development. Chapman \& Hall Publishers, London, UK. 